\title{
The basis and limits of physician authority: a reply to critics
}

\author{
Thomas May University of Minnesota, Minneapolis, USA
}

\begin{abstract}
This paper develops a model of the nurse/physician authority relationship presented in an earlier issue of this journal, and responds to criticisms raised against that model in commentaries on that article. Specifically, I examine the discrepancy which exists between medical knowledge and nursing education, and show this discrepancy to be a difference in type, not quality. The implication is that improvements in nursing education will not affect the authority relationship between physician and nurse. To affect this relationship the nature of nursing education must change.
\end{abstract}

In a recent article published in this journal (1), I offered a model for understanding the duty of a nurse to carry out physician orders when conflicts of judgment arise between physician and nurse. In this paper, I would like to reply to two criticisms of my model of physician authority which have subsequently been published in this journal, in the hope that my reply might help to illuminate and clarify the model I offer. The first criticism, raised by Louise de Raeve (2), questions the basis of physician authority which I propose, and specifically questions the type of authority which this basis implies. The second criticism, raised by Patrick Nash (3), questions the virtue of my model as a device for understanding the limits of physician authority. In its place, Nash offers a model which is supposed to be 'simpler and less contentious'. Let us examine each of these criticisms in turn.

\section{de Raeve's criticism}

In a commentary on my article, Louise de Raeve finds several points of difficulty with the model I offer, but welcomes the opportunity for muchneeded debate on this 'unfashionable topic'. In the spirit of that debate, I would like to offer this reply to de Raeve's difficulties. De Raeve maintains that where I offer a model, based on the work of Joseph Raz, in which a nurse's judgment (in terms of

\section{Key words}

Authority; conscientious objection; medical education. medical treatment) is pre-empted in an authoritative manner by the orders of a physician, a proper model $\vec{*}$ should take a more 'minimalist' interpretation of $\omega$ authority, a model which de Raeve cites from Raz's $\partial$ work as well. On this interpretation, a nurse will not 을 defer decision until she forms her own judgment. $\triangle$ Once such a judgment is formed by nurses, $\subseteq$ 'professionally they are compelled to use it'. Therefore, de Raeve concludes, the argument I offer in which the nurse's judgment is pre-empted (within $\Theta$ certain limitations based upon her skills and. education) must be rejected.

One note on de Raeve's presentation of the 'minimalist' interpretation in Raz: while Raz does in fact present this position in the passage quoted by de Raeve, in the next paragraph Raz soundly rejects this $\varnothing$ position (quite convincingly, I think) as an $\overrightarrow{\vec{O}}$ inadequate model of authority precisely because it 3 'assumes that people are never bounded by authority $\supset$ regarding issues on which they have firm views' (4), when in fact people are bounded by authority in many such cases. This has extremely important implications for de Raeve's view that an increase in medical opinions on the part of nurses will threaten the authority relationship between physician and $O$ nurse. While improvements in nursing education will indeed likely increase opinions on the part of $\frac{}{2}$ nurses concerning medical treatment, the deferment $\rightarrow$ to physician authority will still be justified in the setting of the medical centre.

I think it important that de Raeve agrees in part with my position by conceding that 'where the discrepancy between medical and nursing knowl- $\omega$ edge remains, an authoritative relationship has to persist'. For the very ability to form the judgments ${ }^{\circ}$ necessary for the 'minimalist' interpretation de Raeve favours requires that there not be a wide $?$ discrepancy between the judgments the nurse is ${ }_{0}^{\circ}$ trained to make and the orders which she is to $\vec{D}$ evaluate on the basis of these judgments, otherwise $\frac{\rho}{\Phi}$ she could not make these evaluations well. $\unrhd$ Evidently, where de Raeve disagrees with me is on the issue of the existence or significance of this 8 discrepancy, or at least its continued existence or significance. De Raeve points to the inevitable improvement of nursing education, as well as the $\rightleftharpoons$ 
future introduction of 'nurse prescribers' as a basis for rejecting the model I offer. For example, because nurse prescribers will be trained to make decisions once the sole domain of the physician, the discrepancy between medical knowledge and nursing knowledge will shrink considerably.

If in fact the discrepancy between medical knowledge and nursing knowledge shrinks as de Raeve apparently believes it will, it would indeed undermine the model of physician authority I have offered. For the model I have offered is based upon what the nurse's medical training is designed to do (for the purposes of our problem, to understand the effects which will result from various treatments, but not to determine the best treatment); and what the physician's medical training is designed to do (namely, evaluate what treatment is best). It seems, then, that we have identified the question around which the debate should proceed. Below, I would like to offer my reasons for believing that even in the context of the future changes in nursing education which de Raeve envisions, the discrepancies in medical and nursing knowledge which form the basis of my model will remain.

\section{Types of knowledge}

First, de Raeve seems to have misunderstood the precise nature of the discrepancy between medical and nursing knowledge which serves as the basis of my model of physician authority. This discrepancy is not concerned with the amount or quality of nursing knowledge (perhaps this misunderstanding is what leads de Raeve to find parts of my article 'patronizing'). Rather, it is concerned with the type of knowledge which nursing education is concerned with, and its difference from the type of knowledge which is the concern of the medical education of physicians. Each type of education is designed to enable each professional to do different things. It is a simple fact that the professional education of physicians and nurses is different in this regard, and this difference says nothing about the quality or amount of education each receives. My belief (stated in my earlier paper) that the education of the nurse is a 'complex and sophisticated education' is sincere. The discrepancy between medical and nursing knowledge, however, is a discrepancy in type. No improvement in the quality of nursing education will change this, as the quality of nursing education is simply not the issue.

To undermine the basis of physician authority, the nature of nursing education must change (in a way which dissolves the discrepancy in the type of education nurses and physicians receive). On this point, let us consider the introduction of nurse prescribers. De Raeve repeatedly refers to the introduction of such nurses as a problem for my model of physician authority. These nurses, de Raeve points out, will inevitably have considerable pharmacological knowledge, and this knowledge will 'impinge' on the physician's authority over the prescription of medication. Because these nurses will be trained to make evaluations about what medication should be prescribed, they will not defer judgment to the physicians in any but the 'minimalist' interpretation of authority.

I agree with de Raeve on two points. One, nurse prescribers (when introduced) will inevitably have considerable pharmacological knowledge. And two, because they will have such knowledge and be trained to make decisions concerning what medication is best, they will not have reason to accept a model of authority in which their judgment is pre-empted on this issue. This is entailed by my own model of physician authority, which justifies appeal to the (pre-emptive) authority of the physician on the basis of the fact that the physician is trained to make decisions concerning what treatment is best, and the fact that the nurse is not. If a nurse prescriber is to prescribe medication, she must surely be trained to make evaluations about what medication is best. This training is something which nurses do not currently undergo (at least not as part as their training to be a nurse), and will surely change the relationship between physicians and nurses who undergo this training.

However, while nurse prescribers will surely rise in number (they are bound to, since there are none at the present), there is no reason to believe that they will dominate the profession. As I pointed out in my previous paper, different nurses undergo different training within their profession. This fact is why there are distinctions between Registered Nurses (RNs), Licensed Practical Nurses (LPNs), nursing technicians, etc. That some nurses will undergo a different type of training and become nurse prescribers will not change the fact that many (indeed, I would expect the vast majority of) nurses will not be qualified to become nurse prescribers. There are good reasons to believe this.

First, the extra education which will surely be required in order to be qualified to be a nurse prescriber will offer a disincentive to nurses to get this qualification unless there are identifiable gains to be had from obtaining it. Thus, nurse prescribers will surely find certain 'roles' which they will fill (roles which offer these incentives), and nurses who are either unable, unwilling, or uninterested in filling these roles will not undergo the additional education. Within the medical centre, these roles will surely be much more limited than the roles for more traditional nurses. This is so because a) the medical centre will have to pay nurse prescribers more; b) nurse prescribers will nevertheless in all likelihood find more lucrative employment outside the institution of the medical centre; and c) the daily operation of the medical centre will surely be less complicated when roles are more clearly defined, thus providing incentive for medical centres not to fill traditional 
nursing roles with nurse prescribers (medical centres seldom, for example, hire people qualified to be RNs to fill LPN roles). Thus, I believe that nurses who remain unqualified to be nurse prescribers will continue to constitute the vast majority of nurses in the setting of the medical centre. For these nurses the authoritative relationship between physician and nurse will remain unchanged.

\section{Nash's criticism}

Patrick Nash offers a criticism of the model of physician authority I offer which is different from that of de Raeve. Nash questions whether the model I offer is the best model for understanding the limits of physician authority. Nash believes that a different model for understanding the relationship between physician and nurse is available, one which is 'simpler and less contentious'. Specifically, Nash offers a model for understanding the nurse's duty to question a physician's order which is based on the understanding of each professional's relationship to the hospital, as an employee of that business.

The first problem with Nash's model concerns its applicability, especially in the US (and Nash claims that his model is '.. as apt for the nurse and doctor in the United States ...' as it is in Britain). It is not clear, in the US at least, that the type of simple employer/employee contract Nash seems to envision is applicable. Many US physicians are not employed by medical centres or hospitals. Rather, many have private practices in which they admit patients to a variety of medical centres and hospitals. Nonetheless, some type of contractual relationship does exist (the hospitals must, for example, approve physicians who will work with patients through that hospital, and in this sense the physician is a member of the hospital 'staff', even though this is not an exclusive relationship). The question which must be raised, however, is whether this contractual relationship is so complex as to threaten the virtue of 'simplicity' which Nash feels his model has over my own. I suggest that the different types of relationships between various physicians and hospitals may be such that to understand a nurse's obligations to carry out physician-orders based upon the contractual relationship between medical professionals and hospital, might render the question of obligation so complex that the virtue of simplicity is turned on its head! Would it not be better to have a model for understanding how to address this issue which remained constant no matter what the particular contractual relationship between medical professionals and hospital? This might be better accounted for by reference to the various medical professionals' relationships to the patient, and the purposes which this type of business is meant to serve, as I propose in my own model, rather than through reference to the relationship of employer and employee.
To be fair, we might overlook specific differences in contractual relationships and maintain that all contractual relationships between medical professionals and hospitals contain certain implied fundamental obligations and relationships. This, however, would require a basis or establishing these fundamental features of the contractual relationship between medical professionals and hospital, which is independent of the actual contracts; one which states that no matter what the specific content of these contracts, the relationship between medical professionals and hospitals must contain the presumption of these fundamental obligations. And here, a purely contractual understanding of the nurse's obligation to carry out a physician's orders would be incomplete. It still needs an understanding of when the implied contractual relationships and obligations hold, and when they do not. Nash tells us that a nurse's duty to question a physician's order may '.. from time to time be essential to fulfil the duty of trust to the employer which rules out behaviour likely to undermine his business'. But the most specific model he offers for identifying when these times arise, consists of nurses exercising 'their best judgment as to the reasonableness and safety of treatment' so as to not 'damage the employer's business'. This will surely require greater specification of what considerations are relevant for assessing, particularly, 'reasonability', which leads me to a much deeper issue concerning the contractual model for understanding the relationship between physician and nurse.

Even if the contractual relationship between physician, nurse and hospital could be understood in a way which resolved the above problems, a much deeper issue remains. Specifically, Nash's model might provide a way to address the question of whether there are limits to the nurse's obligation to carry out a physician's orders, but it fails to provide a way to identify the specific circumstances when these limits are applicable. That is, Nash's model does not seem to address adequately the question of when a nurse should not carry out a physician's order. Is it any time she or he disagrees with the physician's order, for any reason? Surely not. Here, a more specific discussion of the reasons to obey, and to refuse to carry out, a physician's order is needed. That is, even if we accept Nash's broad model of the contractual relationship between nurse and physician, we would still require this model to be supplemented by a discussion about how to identify the specific reasons which might justify a nurse's refusal to carry out a physician's order. It would therefore require a model for understanding these reasons, which is precisely what my own model attempts to offer.

The contractual relationship between physician, nurse and hospital contains a relationship of hierarchy. Nash's model does not capture the underlying basis of this hierarchy, and does not $\stackrel{\partial}{\rightleftharpoons}$ 
address the specific reasons why the obligations stemming from that contractual hierarchy might be threatened. Ultimately, I believe, this will require some reference to the health care professional's relationship to the patient. Nash might attempt to account for this: given the specific nature of the medical centre's business, to avoid damaging this business might involve reference to the patient's welfare. But on this model, the patient's welfare imposes a duty on the nurse only indirectly. Does it not seem odd to say that the nurse's obligation to question a physician's order derives ultimately from her obligation not to damage the employer's business (as Nash seems to maintain), rather than deriving this obligation from her responsibilities to the patient in the context of the purpose for which the patient goes to the medical centre (as my own model maintains)?

I do not disagree with Nash's broad standard of the nurse's exercise of judgment as to the reasonableness and safety of treatment. But, besides Nash's application of this standard in a way which considers the welfare of the patient only indirectly, this broad standard is too abstract in Nash's model, and fails to address what might make an order 'unreasonable'. What is needed is a model which outlines the reasons for questioning the obligations imposed by a contractual relationship (especially how the welfare of the patient might directly threaten the contract's applicability!). That is, the question is one of when the contractual relationships between physician, nurse and hospital impose obligations at all, and when the obligations imposed by these contractual relationships are called into question. This is a question which is independent of the actual contractual relationship, and is about the nature of contractual relationships themselves. Focusing on the contractual relationships between physician, nurse and hospital misses the issue in question: the question of when these contractual relationships are even applicable, and does not account for how this question relates to the patient directly.

Nash's model might indeed be both simpler and less contentious than my own. But the simplicity comes at the expense of its usefulness for addressing the types of issues I have just outlined. And its less contentious nature results precisely because it fails to address the serious, and quite controversial, questions surrounding what reasons might undermine the obligations which arise from contractual relationships. Few, I suspect, would disagree about whether there are limitations to physician authority. And the question of these limitations does not arise when nurses and physicians are able to reach agreement. The contentious questions arise when nurses and physicians disagree, and we ask when the nurse should not carry out an order which she disagrees with. Answering this question requires an examination of the reasons why a nurse should carry out a physician's order, and the reasons which might justify a nurse's refusal to carry out a physician's order. It is precisely this which I feel my model of physician authority has to offer.

Thomas May, MA, PhD, is Postdoctoral Fellow at the Center for Biomedical Ethics, University of Minnesota, Minneapolis, USA.

\section{References}

(1) May T. The nurse under physician authority. Fournal of medical ethics 1993; 19: 223-227.

(2) de Raeve L. The nurse under physician authority: commentary. Fournal of medical ethics 1993; 19: 228-229.

(3) Nash P. Doctors and nurses once more - an alternative to May. Fournal of medical ethics 1995; 21: 82-83.

(4) Raz J. The morality of freedom. Oxford: Clarendon Press, 1988: 40.

\section{News and notes}

\section{Ethical Review of Clinical Research}

A conference entitled Ethical Review of Clinical Research will be held from 24-26 September this year at Robinson College, Cambridge in the UK.

The aims of the conference are: to provide practical training for ethics committee members; to bring together those with mutual areas of interest and experience in ethical review, and to provide a forum for discussion of current issues in ethical review.

For further details please contact: Mrs Jill Williams, 7 Foreland Road, Whitchurch, Cardiff CF4 7AR. Telephone/fax: 01222626651. 